\title{
Mechanical Properties of Cast Ti-6Al-4V Lattice Block Structures
}

\author{
QIZHEN LI, EDWARD Y. CHEN, DOUGLAS R. BICE, and DAVID C. DUNAND
}

\begin{abstract}
Ti-6Al-4V lattice block structure panels were fabricated using an aerospace-quality investment casting process. Testing in compression, bending, and impact show that high strength, ductility, and energy absorption are achieved for both individual struts and full panels, despite the intricacies involved with casting fine struts (1.6 or $3.2 \mathrm{~mm}$ in diameter) from a highly reactive, poor-fluidity liquid titanium alloy. The panel stress-strain curve calculated by finite-element modeling correlates well with experimental results, indicating that the occasional defects, which are common to aerospace grade castings and may be present in the struts and nodes, have little detrimental effect on the overall panel compressive properties.
\end{abstract}

DOI: $10.1007 / \mathrm{s} 11661-007-9440-\mathrm{y}$

(C) The Minerals, Metals \& Materials Society and ASM International 2008

\section{INTRODUCTION}

LATTICE-BLOCK structures (LBSs), also called lattice-truss structures, truss-core sandwiches, and cellular lattices, are three-dimensional-periodic reticulated materials that derive their outstanding mechanical performance from a high-symmetry arrangement of internal trusses connected at nodes. ${ }^{[1-6]}$ LBSs have been fabricated from various metallic alloys based on aluminum, ${ }^{[1,5-7]}$ copper, ${ }^{[2,5,8,9]}$ and iron.${ }^{[10-13]}$ Although titanium alloys are attractive candidates for LBS because of their excellent mechanical properties and corrosion resistance, to the best of our knowledge, only one titanium LBS, fabricated by selective electron beam melting, has been reported in the literature to date. ${ }^{[14]}$ Titanium has been used extensively for foam-core sandwich ${ }^{[15-17]}$ and honeycomb structures. ${ }^{[18-20]}$ These structures were processed by powder or foil metallurgy, most likely because of the difficulty of casting highmelting, chemically-reactive, titanium alloys with a high sensitivity to contamination and poor fluidity. There is, however, considerable technical expertise in the investment casting of titanium alloys, with features as small as $1-\mathrm{mm}$ and with high aspect ratios. ${ }^{[21]}$ This opens the door to casting larger-sized, integral, and complexshaped titanium LBSs, combining the regular architecture of LBSs, the high mechanical performance of titanium, and the affordability of castings.

In this article, we report on a structural and mechanical characterization of individual Ti-6Al-4V struts and full Ti-6Al-4V LBS panels produced by an aerospacequality investment casting process. Mechanical tests

QIZHEN LI, Assistant Professor, is with the Chemical and Metallurgical Engineering Department, University of Nevada, Reno, NV 89557. EDWARD Y. CHEN and DOUGLAS R. BICE are with Transition45 Technologies, Orange, CA 92865. DAVID C. DUNAND, Professor, is with the Department of Materials Science \& Engineering, Northwestern University, Evanston, IL 60208. Contact e-mail: dunand@northwestern.edu

Manuscript submitted June 18, 2007.

Article published online January 10, 2008 include compression, tension, bending, and impact tests at ambient and elevated temperatures. The experimental compressive stress-strain behavior of the LBS panels is compared with finite-element modeling predictions.

\section{EXPERIMENTAL PROCEDURES}

\section{A. Panel Processing}

The LBS panels were vacuum cast (a production scale process) using Ti-6Al-4V satisfying the requirements of aerospace specification AMS 4985B. Investment molds from patterns were fabricated for two generic panel architectures: thick panels ( $25 \mathrm{~mm}$ in height) with thick struts (3.2-mm nominal diameter) and thin panels (13 $\mathrm{mm}$ in height) with thin struts $(1.6-\mathrm{mm}$ nominal diameter). Thick panels were cast in two sizes $(100 \times 100$ and $200 \times 200 \mathrm{~mm}^{2}$ ) and thin panels in one size $\left(100 \times 100 \mathrm{~mm}^{2}\right)$. After casting, panels were processed according to the standard aerospace grade titanium casting process (AMS 4985B). Specifically, hot isostatic pressing (HIP) at $900{ }^{\circ} \mathrm{C}$ for 2 hours under a pressure of $103 \mathrm{MPa}$, a treatment commonly used to close casting porosity, ${ }^{[21]}$ was first performed. This was followed by chemical milling to remove $\alpha$-case, NADCAP-approved nondestructive inspection (visual, radiographic, and penetrant), casting weld repair (if necessary), and a mill-anneal heat treatment carried out at $730 \pm 15^{\circ} \mathrm{C}$ for 2 hours, terminated by furnace cooling, and then final inspections and light etching.

Figures 1(a) and (b) show photographs of a $100 \times 100 \mathrm{~mm}^{2}$ thick LBS panel illustrating its architecture. The panel consists of a core with struts arranged in a pyramidal manner and two faces consisting of a square external frame (with approximate $3.8 \times 6.4 \mathrm{~mm}^{2}$ cross section) filled by a triangular planar array of struts. This architecture is similar to that studied by Zhou et al. ${ }^{[5]}$ for a cast Al-alloy LBS panel, with minor modifications to better allow for castability with reactive titanium alloys. The lower right corner of Figure 1(b) 


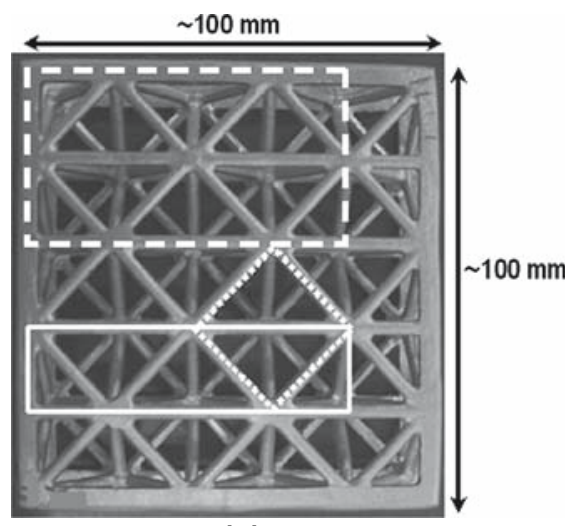

(a)

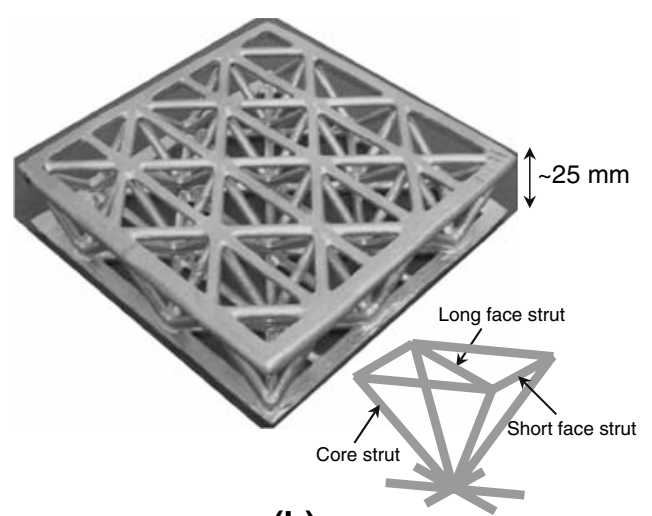

(b)

Fig. 1-Photographs of a $100 \times 100 \mathrm{~mm}^{2}$ thick LBS panel with 25 -mm height. (a) Top view with outline of $2 \times 4$ subpanel (top) used for threepoint bending tests and $1 \times 4$ subpanel (bottom) used for impact tests. $(b)$ Perspective view, with an inset showing schematic of a unit cell (Ref. 5) bounded by the diamond outline in (a), illustrating the three types of struts.

shows the structure unit, which consists of three types of struts: (1) short face struts, (2) long face struts (as well as some half-struts connecting to the frame), and (3) core struts. These struts have lengths of 27,39 , and $31 \mathrm{~mm}$, respectively, calculated between node centers. Nodes within the faces connect 10 struts $(6$ face struts and 4 core struts, Figure 1(b)), nodes along the frame length connect 5 to 6 struts ( 2 to 3 face struts and 3 core struts, Figure 1(b)) and nodes at 4 of the 8 frame corners connect 3 struts (1 face struts and 2 core struts, Figure 1(b)).

Figures 2(a) and (b) show photographs of a $100 \times 100 \mathrm{~mm}^{2}$ thin panel with the same overall architecture as the thick panel, except for the following differences: (1) the frame and nodes have the same size as in thick panels, unlike the strut length and diameter which are reduced compared with those in the thick panels; and (2) the outside-most row of core struts connecting the two frames is missing (Figure 2(b)). Short face struts, long face struts, and core struts have approximate node-to-node lengths of 14, 20, and $16 \mathrm{~mm}$, respectively.

For comparison purposes, a wrought Ti-6Al-4V rod (3.2 $\mathrm{mm}$ in diameter) was purchased from McMaster Carr (Elmhurst, IL) and solid Ti-6Al-4V plates were cast on some of the same casting trees as the panels with thicknesses of 4.1 and $6.3 \mathrm{~mm}$.

\section{B. Strut Mechanical Testing}

Individual struts were cut from thick panels with a diamond saw, and in all cases, their surface was left in the as-received, unmachined state. Strut samples were prepared from these individual struts for compression, tension, bending, and impacting tests, as described subsequently.

Compression tests were conducted on core struts (with their ends machined to assure good parallelism) with aspect ratio of 2.0 to 2.2 at a cross-head speed of $0.2 \mathrm{~mm} / \mathrm{min}$. Strain was measured with a laser extensometer. For tension testing, long face struts, cut

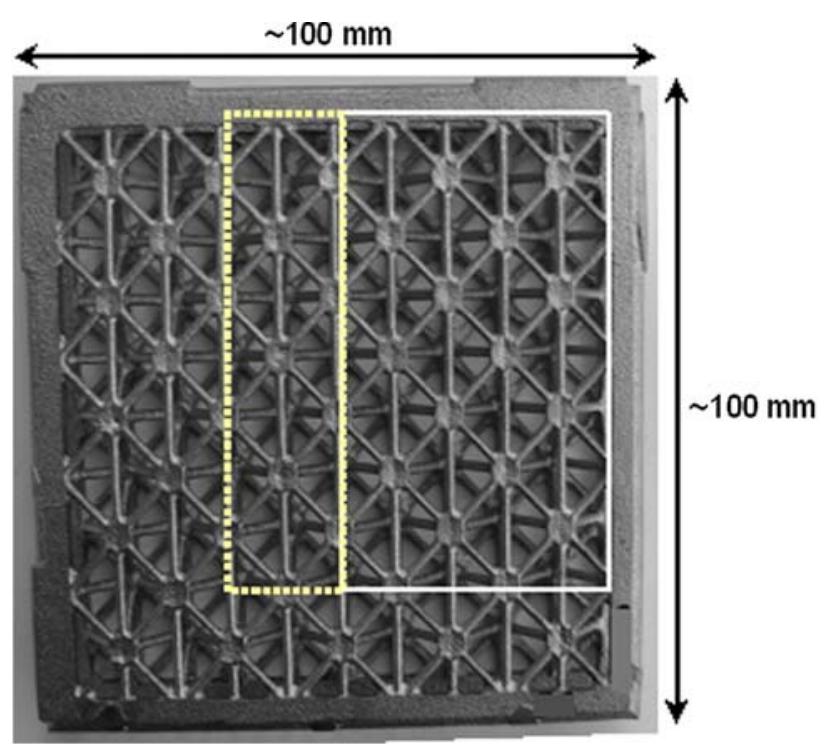

(a)

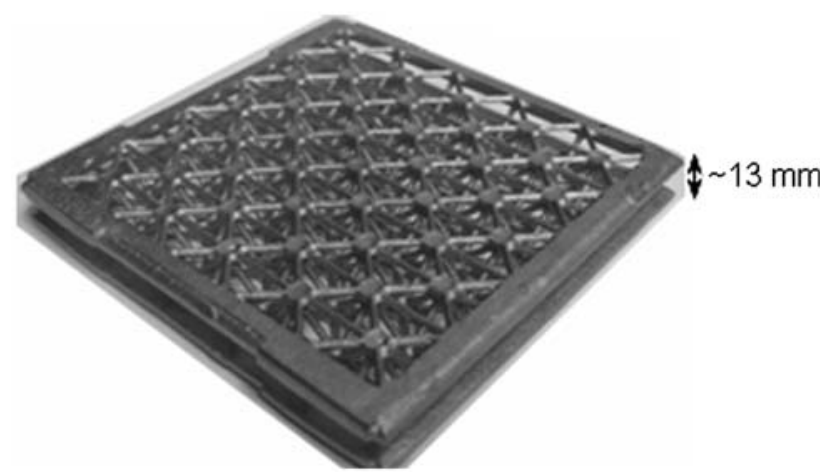

(b)

Fig. 2-Photographs of a $100 \times 100 \mathrm{~mm}^{2}$ thin LBS panel with 13-mm height. (a) Top view with outline of $2 \times 8$ subpanel (left) used for impact test and $5 \times 8$ subpanel (right) used for three-point bending tests. (b) Perspective view. 


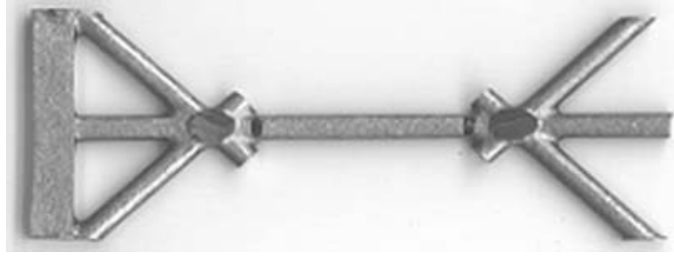

Fig. 3-Photograph of strut sample for tension testing. The long face strut is the gage and the adjacent nodes and face struts are used for gripping.

with adjacent nodes and face struts which were used for gripping (Figure 3), were deformed with a cross-head speed of $0.2 \mathrm{~mm} / \mathrm{min}$. Strain was measured with a clipon extensometer with 12.7-mm gage length. Three-point bend testing was performed on core struts at a crosshead speed of $0.3 \mathrm{~mm} / \mathrm{min}$, using spans of 10.6 , and 10 or $12 \mathrm{~mm}$ for strut from thick and thin panel, respectively. The radius of rollers was $2 \mathrm{~mm}$.

A Tinius Olson IT 504 tester (Horsham, PA) with $23 \mathrm{~J}$ capacity and 26-mm span was used for impact testing of long face struts. The samples were not notched and the cylindrical surface was in the as-cast condition. Impact tests were also performed on the wrought Ti-6Al-4V rod control samples with the same 3.2- $\mathrm{mm}$ diameter as for the thick struts. Testing was performed at ambient and elevated temperature $\left(315^{\circ} \mathrm{C}\right)$. For the later tests, the sample was soaked at $315^{\circ} \mathrm{C}$ in air for 15 minutes, then rapidly removed from the furnace and tested within 10 seconds, to minimize cooling.

\section{Panel Mechanical Testing}

Full-size LBS panels were tested in uniaxial compression at room temperature at a rate of $0.5 \mathrm{~mm} / \mathrm{min}$, using contact extensometry to measure strain. Three-point bending tests were performed on subpanels cut by diamond saw from whole panels. The number of cells was $2 \times 4$ for thick subpanels (Figure $1(\mathrm{a})$ ) and $5 \times 8$ for thin subpanels (Figure 2(a)). The span was $60 \mathrm{~mm}$; the rollers had diameter of $25.4 \mathrm{~mm}$, and the cross-head speed was $0.6 \mathrm{~mm} / \mathrm{min}$, from which deflection was measured.

Impact testing was performed on $1 \times 4$ thick subpanels (Figure 1(a)) and $2 \times 8$ thin subpanel (Figure 2(a)), using a Charpy impact tester (Tinius Olson 1177, Horsham, PA) with $358 \mathrm{~J}$ capacity. Cast solid Ti-6Al$4 \mathrm{~V}$ plates with the same length and mass were also tested. The $1 \times 4$ thick subpanels and cast plates were also tested at $315^{\circ} \mathrm{C}$, with the same heating duration and transfer time as for strut tests.

\section{RESULTS AND DISCUSSION}

\section{A. Macro- and Microstructure}

Table I shows the results of a typical chemical analysis (performed by an outside company) confirming that the chemistry requirements of AMS 4985B were met for an aerospace grade casting.

Nominal density was calculated as the ratio of the panel mass and volume (taken as the outside envelope defined by the upper and lower frames). The nominal density is $0.71 \mathrm{~g} / \mathrm{cm}^{3}$ for all thick panels (except one panel described later) with a strut diameter of $3.2 \mathrm{~mm}$, corresponding to 16 pet of Ti-6Al-4V bulk density $\left(4.43 \mathrm{~g} / \mathrm{cm}^{3[22]}\right)$. The corresponding values are $0.92 \mathrm{~g} / \mathrm{cm}^{3}$ and $21 \mathrm{pct}$ for thin panels with a strut diameter of $1.6 \mathrm{~mm}$. The higher density for the thin panels is because of their relatively larger frame. After deducting the frame mass, the core densities of panels with thick and thin struts are 0.69 and $0.77 \mathrm{~g} / \mathrm{cm}^{3}$, respectively, corresponding to 15.6 and 17 pct relative density.

Strut diameters were measured for the two thick panels subjected to room-temperature compressive testing. Panel A has struts with the nominal value of $3.2 \mathrm{~mm}$, whereas panel B was intentionally cast with thinner struts $(2.9 \mathrm{~mm}$ in diameter), to examine the effect of relative density on mechanical properties. The relative density of panels $A$ and $B$ are 16.0 and 13.1 pet, respectively.

Macroscopically, some of the struts are not exactly cylindrical, i.e., they exhibit small depressions on their surface created by irregularities of the patterns as well as pore closure caused by the HIP process. X-ray inspection confirmed that these shrinkage and gas pores are closed by HIP. The relative density of extracted individual struts was found to be in the range of $100 \pm 2$ pct, indicating little to no porosity after the HIP treatment.

The microstructure of a thick LBS panel was investigated at three different locations by metallographically preparing a node and two strut cross sections (parallel and perpendicular to the strut axis). The node microstructure, shown in Figure 4, is characterized by a Widmanstätten morphology typical of cast Ti-6Al-4V. Micrographs for the two strut orientations are undistinguishable from Figure 4 . The prior- $\beta$ grain size is about $0.5 \mathrm{~mm}$.

\section{B. Strut Mechanical Properties}

The compressive stress-strain curves of three thin and four thick struts tested at room temperature are shown

Table I. Chemical Composition (Weight Percent) of a Ti-6Al-4V Panel and AMS4985B Requirements

\begin{tabular}{lcccccccrrrrr}
\hline Material & $\mathrm{Ti}$ & $\mathrm{Al}$ & $\mathrm{V}$ & $\mathrm{C}$ & $\mathrm{Fe}$ & $\mathrm{Y}$ & $\mathrm{H}$ & $\mathrm{N}$ & $\mathrm{O}$ & OEE* & OET** $^{* *}$ \\
\hline Cast panel & bal & 6.55 & 3.71 & 0.01 & 0.28 & $<0.005$ & 0.0063 & 0.01 & 0.18 & $<0.10$ & $<0.40$ \\
AMS4985B & bal & 5.50 to 6.75 & 3.50 to 4.50 & $<0.10$ & $<0.30$ & $<0.005$ & $<0.015$ & $<0.05$ & $<0.20$ & $<0.10$ & $<0.40$ \\
\hline
\end{tabular}

*Other elements, each.

**Other elements, total. 


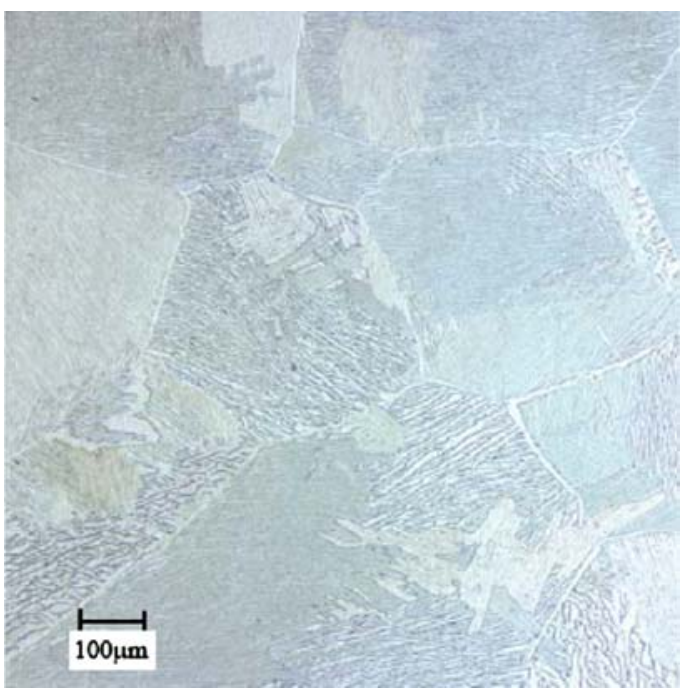

Fig. 4 - Optical micrograph of node cross section.

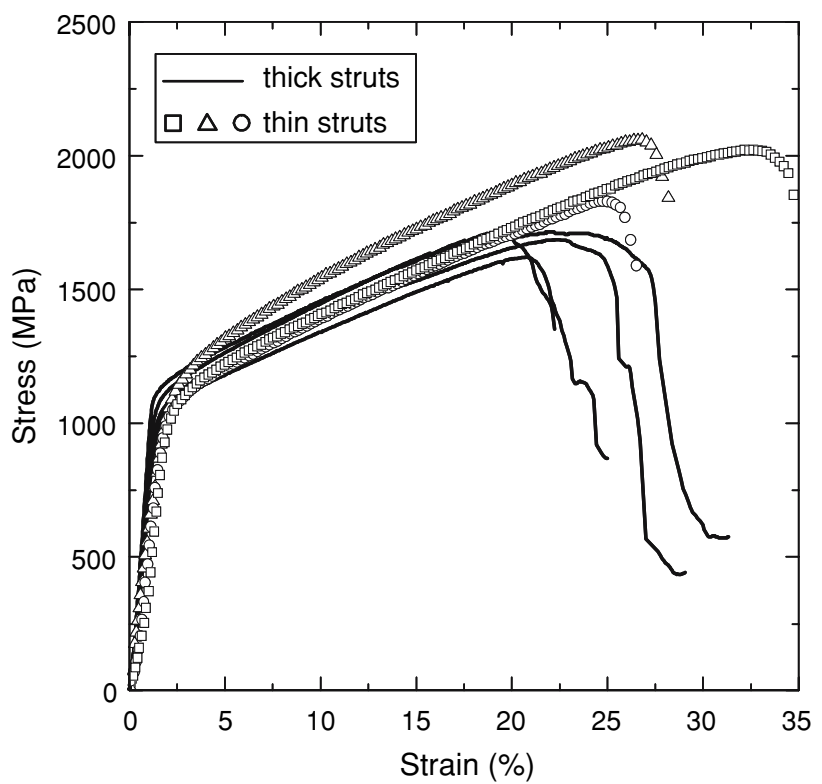

Fig. 5-Compressive stress-strain curves for three thin and four thick struts.

in Figure 5. The corresponding Young's modulus, yield strength, and peak strength are listed in Table II. For thick struts, the Young's modulus is close to the value given by literature; ${ }^{[22]}$ the yield strength is slightly higher than the literature range and the peak strength is within the broad literature range. The yield strength for thin struts is higher than the literature, whereas the peak strength falls in the range given by the literature. The higher yield strength values may be caused by slightly elevated oxygen content for the particular struts tested.

Figure 6 shows tensile stress-strain curves for three thin and two thick struts tested at ambient temperature. Stiffness, strength, and ductility properties determined from the curves are listed in Table II. For thick struts, the Young's modulus and tensile strength are within the literature data range, whereas the yield strength is slightly lower and the elongation and area reduction are higher. The tensile yield strength, ultimate tensile strength, elongation, and area reduction are very close to the literature data for titanium castings.

Load-displacement curves for three-point bending tests performed at ambient temperature on three thin and three thick struts are plotted in Figures 7(a) and (b). The fracture strength $\sigma$ was obtained using ${ }^{[23]}$

$$
\sigma=F \cdot L /\left(\pi R^{3}\right)
$$

where $F$ is the fracture load, $L$ is the sample span, and $R$ is the sample diameter. The fracture strengths were $2220 \pm 231 \mathrm{MPa}$ and $2740 \pm 125 \mathrm{MPa}$ for thin and thick struts, respectively. The lower strength of the thin struts may be explained by their lower tensile ductility (Figure 6 and Table II), leading to early fracture.

The room-temperature impact energy for thick and thin individual struts, averaged over three tests, are $7.7 \pm 0.8$ and $1.4 \pm 0.1 \mathrm{~J}$, respectively. Despite similar diameters, the cast thick struts have about half the impact energy of the wrought Ti-6Al-4V rod $(16.1 \mathrm{~J})$, possibly as a result of the finer-grained microstructure imparted by wrought processing. The impact energies per unit area, obtained by dividing the impact energy by the cross-sectional area of each type of strut, are 2.0, $0.95 \pm 0.1$, and $0.69 \pm 0.05 \mathrm{~J} / \mathrm{mm}^{2}$ for wrought $\mathrm{rod}$, thick strut, and thin strut samples, respectively. It is apparent that the thin struts absorb less energy than the thick struts, probably because of their lower bending strength and ductility.

For impact testing performed at $315{ }^{\circ} \mathrm{C}$, the impact energy for a wrought rod is $14.1 \mathrm{~J}$ and those for the thick and thin struts are $12.6 \pm 0.1$ and $1.2 \pm 0.1 \mathrm{~J}$,

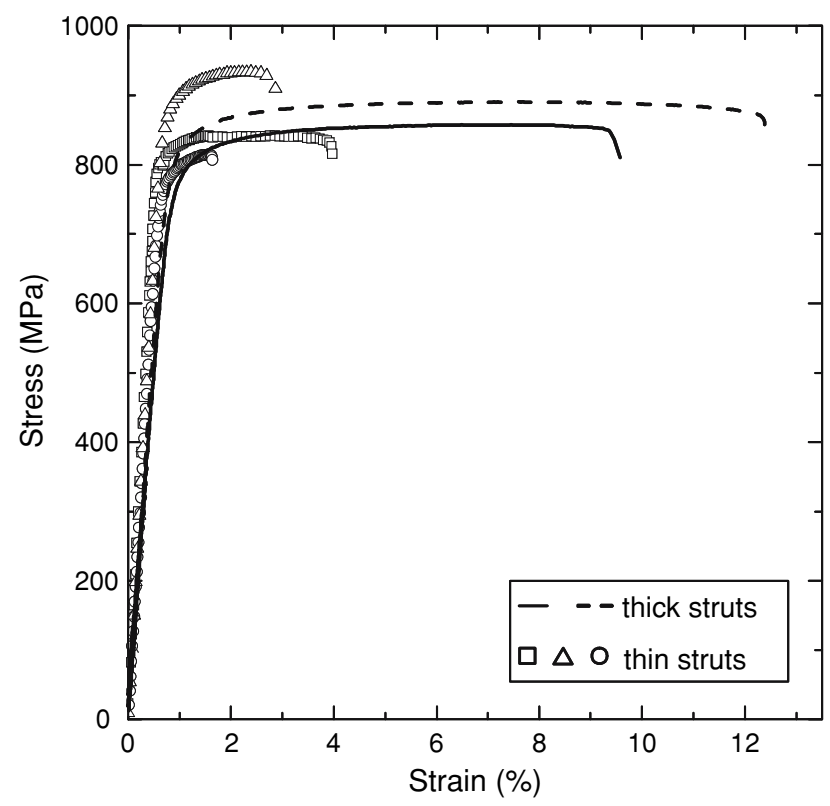

Fig. 6-Tensile stress-strain curves for three thin and two thick struts. 
Table II. Strut Compressive and Tensile Properties (Error Range Corresponds to Standard Deviation)

\begin{tabular}{|c|c|c|c|c|c|}
\hline Sample & $\begin{array}{c}\text { Young's } \\
\text { Modulus (GPa) }\end{array}$ & $\begin{array}{l}\text { Yield Strength } \\
(\mathrm{MPa})\end{array}$ & $\begin{array}{c}\text { Ultimate } \\
\text { Strength (MPa) }\end{array}$ & $\begin{array}{l}\text { Elongation } \\
\text { (Pct) }\end{array}$ & $\begin{array}{l}\text { Area of Reduction } \\
\text { (Pct) }\end{array}$ \\
\hline \multicolumn{6}{|l|}{ Compression } \\
\hline Thin struts & $*$ & $1030 \pm 60$ & $1970 \pm 123$ & - & - \\
\hline Thick struts & $93 \pm 7$ & $969 \pm 93$ & $1680 \pm 44$ & - & - \\
\hline Ti-6Al-4V ${ }^{[22]}$ & 105 to 116 & 825 to 895 & 1380 to 2070 & - & - \\
\hline \multicolumn{6}{|l|}{ Tension } \\
\hline Thin struts & $*$ & $827 \pm 53$ & $864 \pm 62$ & $3 \pm 1$ & $12 \pm 4$ \\
\hline Thick struts & $110 \pm 5$ & $782 \pm 34$ & $875 \pm 23$ & $11 \pm 2$ & $16 \pm 2$ \\
\hline Ti-6Al-4V $[22]$ & 105 to 116 & 813 & 917 & 8 & 13 \\
\hline
\end{tabular}

*Samples are too small for accurate measurement.

respectively. The impact energies per unit area are 1.8 , $1.6 \pm 0.01$, and $0.60 \pm 0.05 \mathrm{~J} / \mathrm{mm}^{2}$, respectively. The average impact energy of the thick struts is close to that for wrought rods, but as for ambient temperature tests, the impact energy of the thin struts is reduced.

In summary, the compressive, tensile, and bending properties of the thick struts are comparable with those found in literature data, whereas the impact energy at ambient temperature of both thick and thin struts is significantly reduced as compared with wrought Ti-6Al-4V. However, at elevated temperature, the thick struts show little difference in impact energy as compared with wrought Ti-6Al-4V.

\section{Panel Compressive Properties}

Figure 8 illustrates the compression stress-strain curves at room temperature for the two thick panels that exhibit different strut diameters $(2.9$ and $3.2 \mathrm{~mm})$, mass and relative density, listed in Table III. Corresponding panel elastic modulus, yield strength, and maximum strength are listed in Table III. The heavier, denser panel A, with $3.2-\mathrm{mm}$ struts, is about $50 \mathrm{pct}$ stronger than the lighter, less dense panel $\mathrm{B}$, with 2.9-mm struts. When normalizing the yield strength by the panel mass, panel $\mathrm{A}$ is about 20 pet stronger than panel B. Figure 9 shows a photograph of the tested panel $\mathrm{B}$, showing that uniaxial compressive deformation occurs by bending/buckling of the struts. A likely reason for the lower strength of panel B is that the mass of its low-load-bearing frame is the same as panel A, but the mass of its high-load-bearing struts is less.

The yield strength of panel $\mathrm{A}$ is about 3.0 pct of the compressive yield strength of its struts (29 MPa vs $1030 \mathrm{MPa})$. Zhou et al..$^{[5]}$ reported tests done on both struts and panels cast of an aluminum alloy with major element concentration closest to aluminum alloy 516.1 and 518.0. This panel is similar in design to ours in terms of base configuration, with a similar unit cell architecture, the same strut diameter of $3.2 \mathrm{~mm}$, and a somewhat lower relative density of 13.1 pct. Their struts yield in compression at $118 \mathrm{MPa}$ and their panel yields at about 3.4 MPa (average of three tests), corresponding to 2.9 pct of the strut compressive yield strength. This ratio is close to the value found for our panel A $(3.0 \mathrm{pct})$, with a relative density of 16 pct. In absolute

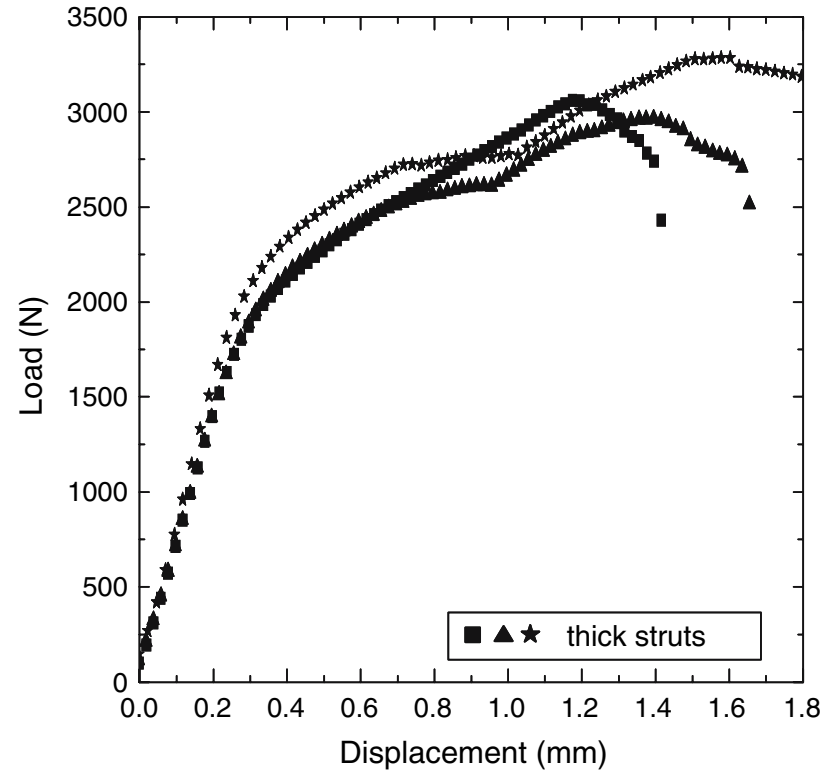

(a)

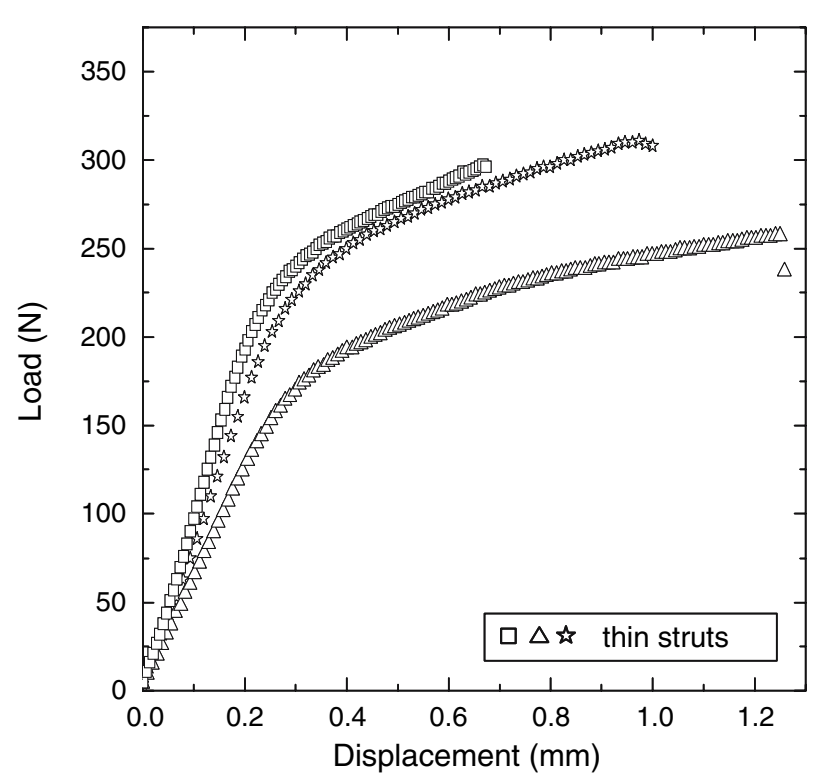

(b)

Fig. 7-Bending load-displacement curves for $(a)$ three thick struts and $(b)$ three thin struts. 


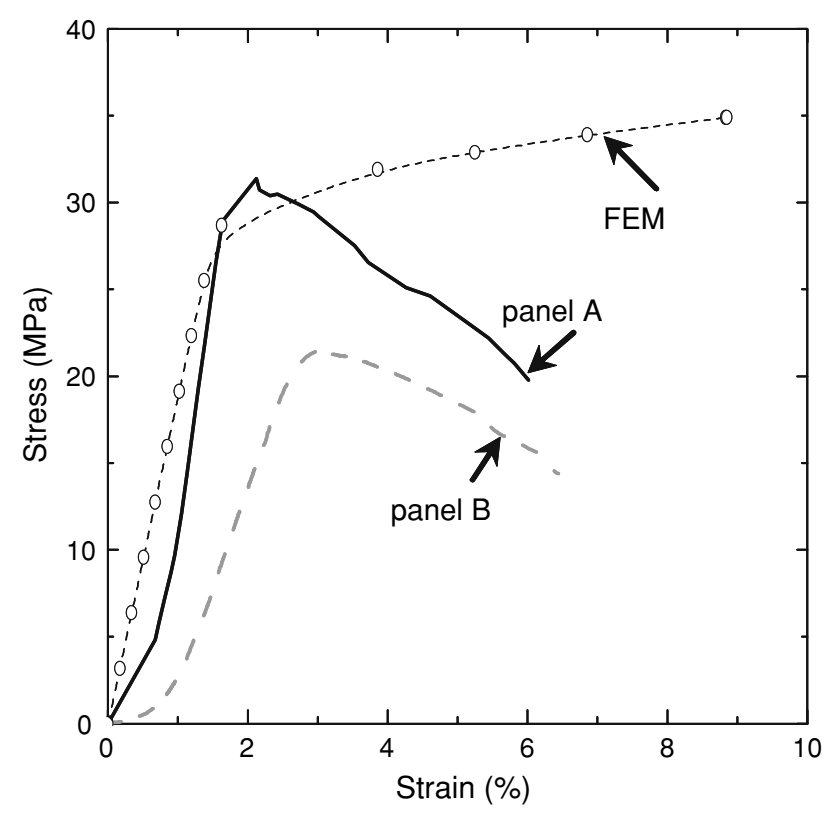

Fig. 8-Experimental compressive stress-strain curves thick panels A and $\mathrm{B}$ of different masses (strut diameters) and curve predicted by FEM for panel A.

terms, the present titanium LBS panel shows a factor -8.5 improvement in compressive strength as compared with the above aluminum panel, reflecting the factor -8.7 improvement in strut compressive strength; however, the mass increase is only a factor $\sim 2$.

There has been, to our knowledge, only one titaniumbased lattice block structure reported in the literature to date that was created by selective electron beam melting. Using this method, where metal powders are selectively melted layer by layer under high vacuum, Heinl et al. ${ }^{[14]}$ created a structure based on a diamond lattice, with struts about $0.4 \mathrm{~mm}$ in diameter and $1.4 \mathrm{~mm}$ in length. The strut surface was very rugged, probably because of incomplete densification of the powders during the process. The structure, with a relative density of about 20 pct, showed yield strengths (17 to $23 \mathrm{MPa}$ ) comparable with the $19 \mathrm{MPa}$ value measure on our panel $\mathrm{B}$ with a lower relative density of 13 pct, but less than the $29 \mathrm{MPa}$ yield strength achieved by panel A at a lower relative density of 16 pct. Direct comparison is, however, not possible, because of the different spatial arrangement of the beams and the absence of any frames in the structure studied by Heinl et al. ${ }^{[14]}$

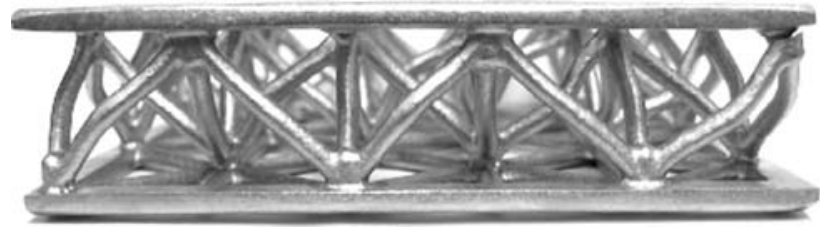

Fig. 9-Photograph of panel B with thick struts deformed under compression.

Stiffness and strength results for the present panels can be compared with analytical predictions by Deshpande et al., ${ }^{[6]}$ who modeled an octet-truss structure with a structure similar to the present LBS panels, except for the fact that four face struts converge on face nodes, rather than the six in the present panels. The compressive stiffness $E_{33}$ of the octet-truss structure is given by ${ }^{[6]}$

$$
E_{33}=\frac{\bar{\rho}}{5} E_{S}
$$

where $\bar{\rho}$ is the relative density and $E_{s}$ is the Young's modulus of the solid material. Using the upper bound of measured strut modulus $E_{s}=100 \mathrm{GPa}$ (close to the $105 \mathrm{GPa}$ lower bound for bulk Ti-6Al-4V, Table III), Eq. [2] predicts stiffness values for panels A and B (with 13.1 and 16.0 pet relative densities) of 2.7 and $3.2 \mathrm{GPa}$, respectively, as compared with measured values of 1.2 and $2.9 \mathrm{GPa}$ (Table III), respectively. Deshpande et al. ${ }^{[6]}$ also found that Eq. [2] overpredicted the modulus of a cast aluminum alloy LBS panel, which they attributed to the "bedding-in" of the struts into the nodes during the initial stages of deformation. Additionally, the present panels exhibit nodes that are thicker than in the model, as well as additional face struts, which both reduce their stiffness as compared with Eq. [2].

Deshpande et al. ${ }^{[6]}$ also developed an equation for the uniaxial yield strength $\sigma_{33}$ of octet-truss structures as

$$
\sigma_{33}=2 \sqrt{2 \pi}(a / l)^{2} \sigma_{Y}
$$

where $a$ and $l$ are the strut radius and the node-to-node length, respectively, and $\sigma_{Y}$ is the yield strength of the solid. Using the experimental truss values $\sigma_{Y}=1030$ \pm 60 and $969 \pm 93 \mathrm{MPa}$ (Table III), $a=1.45$ and $1.6 \mathrm{~mm}$, and $l=31 \mathrm{~mm}$, Eq. [3] predicts panel yield strengths of $19 \pm 2$ and $24 \pm 2 \mathrm{MPa}$ for panels B and A. There is reasonable agreement with measured yield strengths of 19 and $29 \mathrm{MPa}$ (Table III), despite the

Table III. Thick Panel Compressive Properties

\begin{tabular}{lccccccc}
\hline & $\begin{array}{c}\text { Strut } \\
\text { Diameter } \\
(\mathrm{mm})\end{array}$ & $\begin{array}{c}\text { Mass } \\
(\mathrm{g})\end{array}$ & $\begin{array}{c}\text { Density } \\
\left(\mathrm{g} / \mathrm{cm}^{3}\right)\end{array}$ & $\begin{array}{c}\text { Relative } \\
\text { Density } \\
(\mathrm{Pct})\end{array}$ & $\begin{array}{c}\text { Elastic } \\
\text { Modulus* } \\
(\mathrm{GPa})\end{array}$ & $\begin{array}{c}\text { Yield } \\
\text { Strength } \\
(\mathrm{MPa})\end{array}$ & $\begin{array}{c}\text { Maximum } \\
\text { Load } \\
(\mathrm{kN})\end{array}$ \\
\hline A & 3.2 & 161 & 0.71 & 16.0 & 2.9 & 29 & 289 \\
$\mathrm{~B}$ & 2.9 & 139 & 0.59 & 13.1 & 1.2 & 19 & 200 \\
\hline
\end{tabular}

*Maximum tangent modulus. 
additional face struts found in the present panels but absent in the structure modeled in Eq. [3], as discussed previously.

\section{Panel Bending and Impact Properties}

Figure 10 gives the load-displacement curve for bending tests performed at ambient temperature on a $2 \times 4$ thick subpanel and a $5 \times 8$ thin subpanel. The fracture strengths, $\sigma_{\max }$, are 110 and $71 \mathrm{MPa}$, respectively, using the equation ${ }^{[23]}$

$$
\sigma_{\max }=3 \cdot F_{\max } \cdot L /\left(2 \cdot w \cdot h^{2}\right)
$$

where $F_{\max }$ is the maximum (fracture) load, and $L, w$, and $h$ are the span, width, and height of the sample. The mass of the two subpanels are 46 and $27 \mathrm{~g}$, respectively. If normalizing the fracture strength by the sample mass, the thin subpanel has larger fracture strength per unit mass, indicating better bending resistance. Figure 11 is a

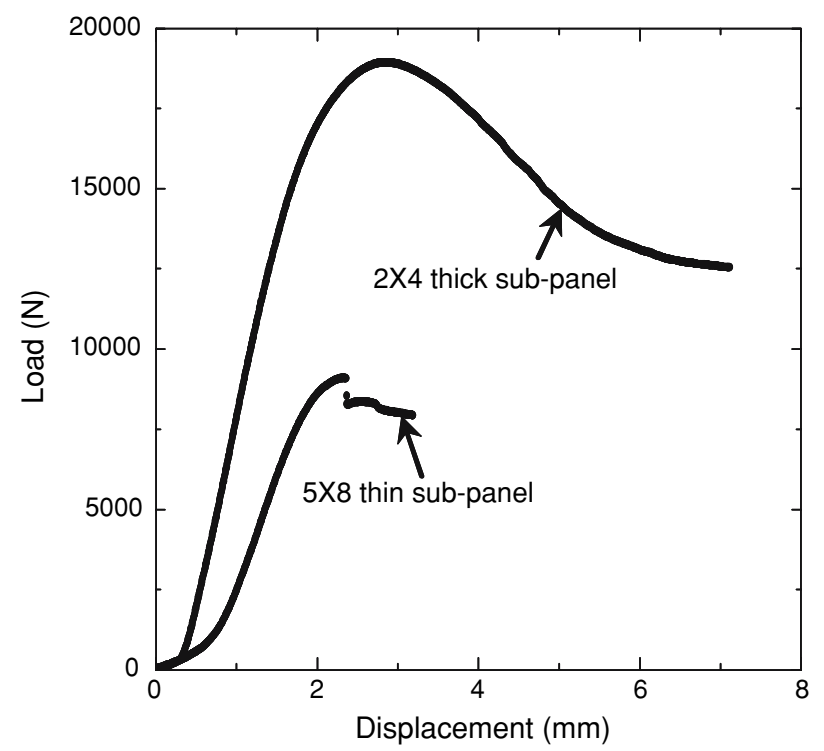

Fig. 10 -Bending load-displacement curves for $2 \times 4$ thick and $5 \times 8$ thin subpanels.

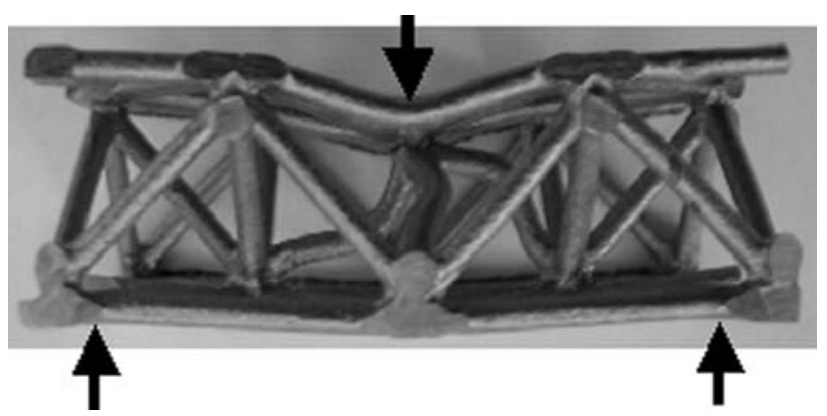

Fig. 11-Photograph of a $2 \times 4$ thick subpanel after bending deformation. The two bottom arrows show the supporting rollers and the top arrow the loading roller.
Table IV. Mass, Testing Temperature, and Impact Energy for Thick Subpanel, Thin Subpanel, and Solid Plate Samples

\begin{tabular}{lccc}
\hline Sample & $\begin{array}{c}\text { Testing } \\
\text { Temperature } \\
\left({ }^{\circ} \mathrm{C}\right)\end{array}$ & $\begin{array}{c}\text { Mass } \\
(\mathrm{g})\end{array}$ & $\begin{array}{c}\text { Impact } \\
\text { Energy* } \\
(\mathrm{J})\end{array}$ \\
\hline $1 \times 4$ thick subpanel 1 & 25 & 29 & 296 \\
$1 \times 4$ thick subpanel 2 & 25 & 31 & 288 \\
Plate (6.3-mm thick) & 25 & 31 & 52 \\
$2 \times 8$ thin subpanel & 25 & 11 & 61 \\
Plate (4.1-mm thick) & 25 & 11 & 24 \\
$1 \times 4$ thick subpanel & 315 & 31 & 357 \\
Plate (6.3-mm thick) & 315 & 31 & 114 \\
\hline
\end{tabular}

*Error: $\pm 0.7 \mathrm{~J}$.

photograph of the $2 \times 4$ thick subpanel after deformation. Plastic deformation is very inhomogeneous, with the upper roller locally deforming the ductile face struts in the upper frame and some of the underlying core struts.

The impact energies for all subpanel and plate samples are listed in Table IV, together with their masses. At room temperature, the average impact energies are 292 and $61 \mathrm{~J}$ for thick and thin subpanels, respectively. The impact energies for plate samples with the same mass as the above two subpanels are 52 and $24 \mathrm{~J}$, respectively, illustrating the very large improvement (by a factor of 2.5 to 5.6) in energy absorption achievable with the lattice architecture. At $315^{\circ} \mathrm{C}$, the impact energy of the thick lattices thick panel is $357 \mathrm{~J}$, corresponding to increases by a factor of 1.2 as compared with the same lattice as ambient temperature, or a factor 3.1 for the solid plate at the same temperature.

After normalization by their mass, the thick subpanels absorb about twice the energy per unit mass of the thin subpanels. This result is expected, given the much lower tensile (and bending) ductility of the thin struts as compared with the thick struts, and the higher height (and bending stiffness) of the thick panels.

\section{E. Finite-Element Modeling of Panel Compressive Properties}

The finite element model has $97 \times 97 \times 22 \mathrm{~mm}^{3}$ overall dimensions with cylindrical struts $3.2 \mathrm{~mm}$ in diameter, closest to the thick panels with $100 \times 100 \times 25 \mathrm{~mm}^{3}$ dimensions and the same average diameter struts. The commercial software ABAQUS (version 6.5-1, Providence, Rhode Island) is employed for the analysis. A total of 52,822 linear tetrahedral elements are used in the model. Two analytical rigid plates are in contact with the surfaces of the panel and the load is applied on one plate with the other plate fixed. The mechanical behavior of the material in the model is taken to be the average of the four compressive tests on thick struts shown in Figure 5: linear elastic behavior with a slope of $100 \mathrm{GPa}$ up to the yield strength of $969 \mathrm{MPa}$, followed by linear plastic behavior with a slope of $3.56 \mathrm{GPa}$ 
(corresponding to a flow stress of $1680 \mathrm{MPa}$ at strain of 0.2$)$.

A uniaxial compressive load is applied to the model up to a maximum value of $328 \mathrm{kN}$. The FEM stressstrain curve is shown in Figure 8, and predicts the measured curve for the thick panel A, for stresses up to the yield stress, relatively well. The FEM Young's modulus is $2.0 \mathrm{GPa}$ (vs $2.9 \mathrm{GPa}$ measured for panel $\mathrm{A}$ ), and the FEM yield stress is $28.7 \mathrm{MPa}$ ( vs $29 \mathrm{MPa}$ ). The softening experimentally observed beyond the maximum stress of panel A is not predicted by the model. Deshpande et al. ${ }^{[6]}$ also found a similar discrepancy between experimental and FEM stress-strain curves, which was assigned to the onset of plastic buckling of the struts, a phenomenon observed here as well.

Calculated von Mises stress and plastic strain contours are given in Figures 12, 13, and 14 for loads of 60,240 , and $328 \mathrm{kN}$, respectively, corresponding to stresses of $6.4,25.5$, and $34.9 \mathrm{MPa}$. These figures show that the core struts experience the highest stresses and strains, as expected. At the lowest stress of $6.4 \mathrm{MPa}$ (in the elastic range of the panel stress-strain curve), there is no plastic strain anywhere in the model and the stresses within the core struts are relatively uniform (Figure 12). At the intermediate stress of $25.5 \mathrm{MPa}$ (just below the $29 \mathrm{MPa}$ yield stress of the panel), stress and strain concentrations are visible at the nodes and in the struts near the nodes (Figures 13(a) and (b)). Only a very few elements near the nodes show nonzero plastic strain. Finally, at the highest stress of $34.9 \mathrm{MPa}$ (well into the plastic range of the panel), these stress concentrations remain (Figures 14(a) and (b)) and the core trusses deform by bending-buckling (Figure 14(c)), consistent with experimental observation (Figure 9).

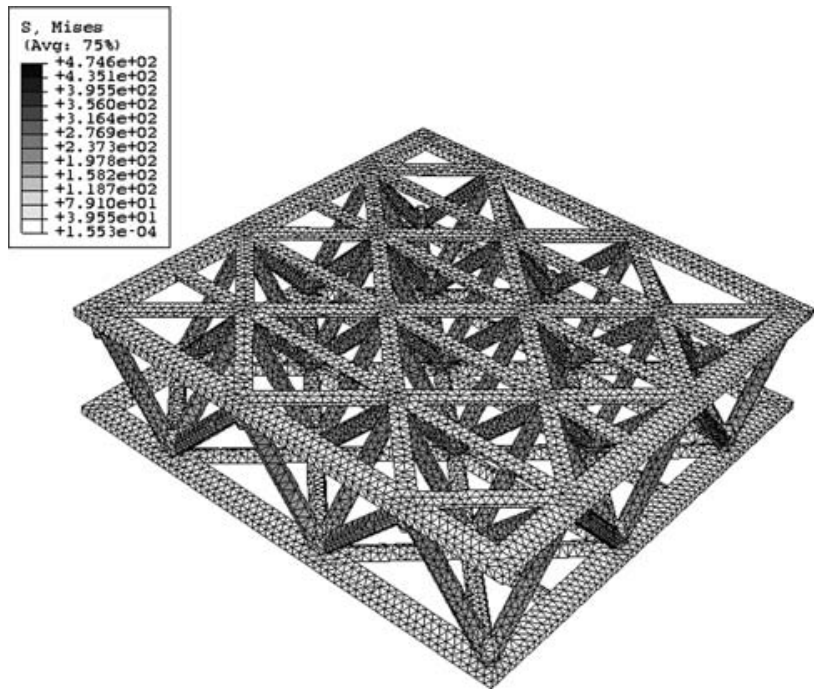

Fig. 12-Contour plot of von Mises stress for thick panel under a compressive load of $60 \mathrm{kN}$.
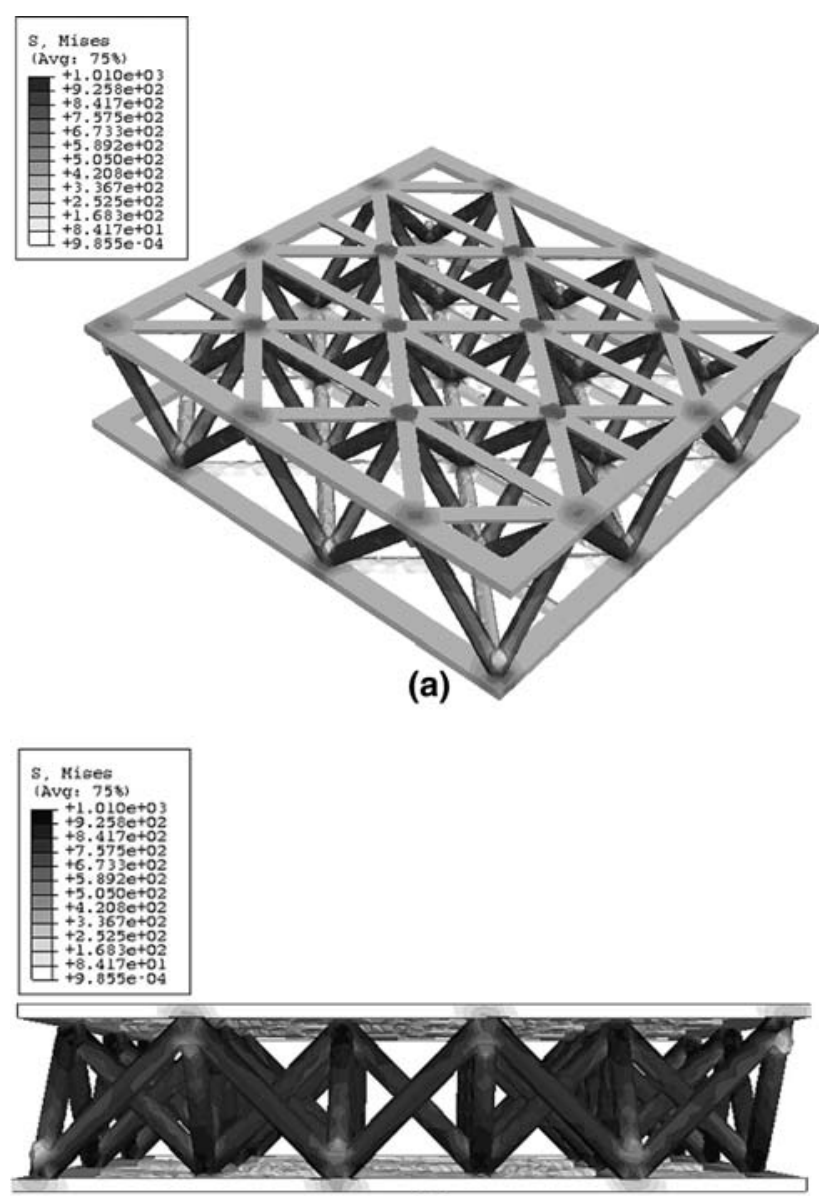

(b)

Fig. 13 - Contour plots of von Mises stress for thick panel under a compressive load of $240 \mathrm{kN}$ : (a) perspective view and $(b)$ side view.

\section{CONCLUSIONS}

Aerospace-quality Ti-6Al-4V lattice block structures have been produced (for the first time, to the best of our knowledge) by investment casting. This processing method has many advantages as compared with other possible fabrication processes, including powder-base methods, especially as potential issues such as the presence of casting defects and their effects on lattice properties are minimized or may be even eliminated as the process matures.

Microstructural examination and mechanical testing of individual struts show that casting porosity is rare, and the nominal mechanical properties of cast Ti-6Al$4 \mathrm{~V}$, in particular, its high strength, ductility, and impact resistance, are maintained.

Compression tests indicate that the panel strength and stiffness are in general agreement with predictions from analytical and finite-element models. Good strength and ductility are achieved in quasi-static bending of subpanels and, under impact conditions at ambient and elevated temperatures, subpanel absorbs much more energy than a solid Ti-6Al-4V plate of the 


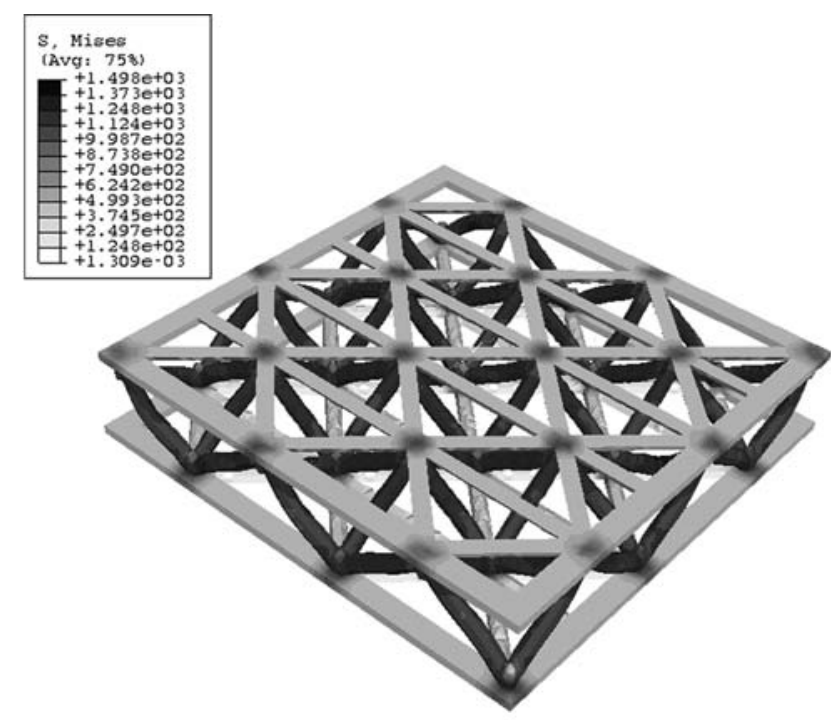

(a)

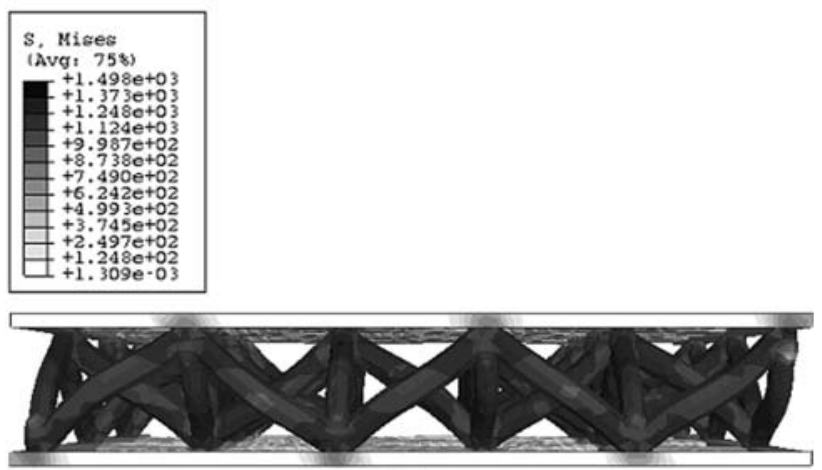

(b)

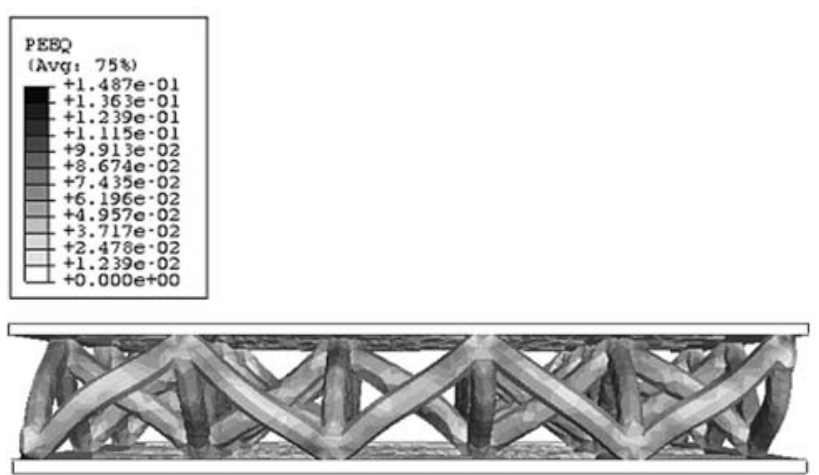

(c)

Fig. 14 Contour plots for thick panel under a compressive load of $328 \mathrm{kN}$. (a) Perspective view of von Mises stress, (b) side view of von Mises stress, and $(c)$ side view of effective plastic strain.

\section{ACKNOWLEDGMENTS}

This work was supported by NASA-Glenn Research Center through Contract No. NNC04CA14C with guidance and encouragement from Drs. S.A. Padula II, M.V. Nathal, and S.L. Bowman. The authors also acknowledge Professors S.A. Guralnick and S. Mostovoy (Illinois Institute of Technology) for use of, and help with, panel compressive testing equipment.

\section{REFERENCES}

1. J.C. Wallach and L.J. Gibson: Int. J. Solids Struct., 2001, vol. 38, pp. 7181-96.

2. S. Chiras, D.R. Mumm, A.G. Evans, N. Wicks, J.W. Hutchinson, K. Dharmasena, H.N.G. Wadley, and S. Fichter: Int. J. Solids Struct., 2002, vol. 39, pp. 4093-4115.

3. F.W. Zok, H.J. Rathbun, Z. Wei, and A.G. Evans: Int. J. Solids Struct., 2003, vol. 40, pp. 5707-22.

4. N. Wicks and J.W. Hutchinson: Mech. Mater., 2004, vol. 36, pp. 739-51.

5. J. Zhou, P. Shrotriya, and W.O. Soboyejo: Mech. Mater, 2004, vol. 36, pp. 723-37.

6. V.S. Deshpande, N.A. Fleck, and M.F. Ashby: J. Mech. Phys. Solids, 2001, vol. 49, pp. 1747-69.

7. D.J. Sypeck: Metall. Mater. Trans. B, 2005, vol. 36B, pp. 125-31.

8. K. Tantikom, T. Aizawa, and T. Mukai: Int. J. Solids Struct., 2005, vol. 42, pp. 2199-2210.

9. J. Wang, A.G. Evans, K. Dharmasena, and H.N.G. Wadley: Int. J. Solids Struct., 2003, vol. 40, pp. 6981-88.

10. D.T. Queheillalt and H.N.G. Wadley: Metall. Mater. Trans. A, 2005, vol. 39A, pp. 132-37.

11. D.T. Queheillalt and H.N.G. Wadley: Acta Mater., 2005, vol. 53, pp. 303-13.

12. F.W. Zok, H.J. Rathbun, M. He, E. Ferri, C. Mercer, R.M. McMeeking, and A.G. Evans: Philos. Mag., 2005, vol. 85, pp. 3207-34.

13. H.J. Rathbun, F.W. Zok, S.A. Waltner, C. Mercer, A.G. Evans, D.T. Queheillalt, and H.N.G. Wadley: Acta Mater., 2006, vol. 54, pp. $5509-18$.

14. P. Heinl, A. Rottmair, C. Körner, and R.F. Singer: Adv. Eng. Mater., 2007, vol. 9, pp. 360-64.

15. D.M. Elzey and H.N.G. Wadley: Metall. Mater. Trans. A, 1999, vol. 30A, pp. 2689-99.

16. D.T. Queheillalt, B.W. Choi, D.S. Schwartz, and H.N.G. Wadley: Metall. Mater. Trans. A, 2000, vol. 31A, pp. 261-73.

17. D.C. Dunand: Adv. Eng. Mater., 2004, vol. 6, pp. 369-76.

18. W.B. Han, K.F. Zhang, G.F. Wang, and X.J. Zhang: J. Mater. Sci. Technol., 2005, vol. 21, pp. 60-62.

19. X. Huang and N.L. Richards: Welding J., 2004, vol. 83, pp. 73S$81 \mathrm{~S}$.

20. J. Pilling and N. Ridley: Superplasticity in Crystalline Solids, The Institute of Metals, London, 1989, pp. 175-195.

21. L. Nastac, M.N. Gungor, I. Ucok, K.L. Klug, and W.T. Tack: Int. J. Cast Met. Res., 2006, vol. 19, pp. 73-93.

22. R. Boyer, G. Welsch, and E.W. Collings: Materials Properties Handbook: Titanium Alloys, ASM INTERNATIONAL, Materials Park, OH, 1994, pp. 494-526.

23. S.P. Timoshenko and J.M. Gere: Mechanics of Materials, D. Van Nostrand Company, New York, NY, 1972, pp. 113-119. same mass; this indicates that the casting process did not lead to deterioration of the alloy mechanical properties. 